\title{
Lacustrine Carbonate Reservoir Characteristics Research of Jurassic Da'anzhai Member in North Central Sichuan Basin
}

\author{
Du Jiangmin ${ }^{1,2, *}$, Zhang Xiaoli ${ }^{1}$, Yu Yanqiu ${ }^{2}$, Huang Kaiwei ${ }^{3}$, Guo Hongguang ${ }^{4}$, Zhong Gaorun $^{1}$, \\ Yu Bowei ${ }^{1}$ and Zhao Yuanyuan ${ }^{2}$
}

${ }^{I}$ State Key Laboratory of Continental Dynamics/ Department of Geology, Northwest University, Xi'an, Shanxi, 710069, P.R. China; ${ }^{2}$ College of Resources, Shijiazhuang University of Economics, Shijiazhuang, Hebei, 050031, P.R. China; ${ }^{3}$ Northeast SiChuan High-Sour Gas field Development and Construction Project Divison, Petro China Southwest Oil \& Gas Field, Chengdu, Sichuan, 610051, P.R. China; ${ }^{4}$ CNPC Logging Changqing Business Division, Xi'an, Shanxi, 710201, P.R. China

\begin{abstract}
Based on both macroscopic and microscopic characteristics of cores from Lower Jurassic Da'anzhai Member in north central Sichuan Basin, and combined with physical property data, a detail study has been conducted, which includes reservoir characteristics such as lithologic characters, physical properties, and reservoir space types, and control factors of reservoir development. The study suggests that, there are two typical kinds of reservoirs: crystalline shell limestone and argillaceous shell limestone. The reservoirs properties are poor with ultra-low porosity and low permeability, which can be significantly improved by fractures. Reservoir space type is pore-fracture, mainly constitutive of the micro-fractures accompanied by dissolved pores. The reservoir development is controlled by sedimentation, diagenesis and tectogenesis together. Shell beach and lacustrine slop are the favorable facies for reservoir development. Dissolution is the primary constructive diagenesis to improve reservoir porosity and permeability. Structural fractures are necessary for reservoir effectiveness and high production.
\end{abstract}

Keyword: Control factor, Da'anzhai member, Lower Jurassic, North central Sichuan Basin, Reservoir characteristics.

\section{INTRODUCTION}

Due to the limited distribution and quantity, lacustrine carbonate reservoir didn't arouse attentions from petroleum geologists at first. Therefore, study of lacustrine carbonate reservoir is relatively lagging behind when compared with marine carbonate reservoir. As more lacustrine carbonate hydrocarbon reservoirs had been discovered in China and abroad, relevant researches have been further conducted. According to the third round of petroleum resources assessment of China, hydrocarbon resources from lacustrine carbonate reservoirs are approximately $45 \times 10^{8} \mathrm{t}$, which suggest a considerable exploration potential.

Jurassic Da'anzhai member in Sichuan Basin is a typical lacustrine carbonate hydrocarbon bearing formation [1]. Predecessors have carried out a number of researches and got some achievements [2-4]. But for north central Sichuan Basin, the exploration degree is relatively low and pertinent researches are just beginning in recent years [5, 6]. Currently in this area, hydrocarbon shows are active and reservoirs are widespread, but the oil and gas productions are low. The author hopes that through this study of lacustrine carbonate reservoir characteristics and control factors of $\mathrm{Da}$ 'anzhai

\footnotetext{
*Address correspondence to this author at the Department of Geology, Northwest University, Xi'an, Shanxi, 710069, P.R. China;

Tel: +86 15230163012; Fax: +86 31187208285 ;

E-mail: jiangmindu@163.com
}

member in north central Sichuan Basin, some references of lacustrine carbonate reservoirs in this area and even in China can be provided.

\section{REGIONAL GEOLOGY}

The north central Sichuan Basin is including Bazhong, Yilong, Pingchang, Yingshan and other counties, which, on regional tectonic background, belong to Yilong-Pingchang gentle structure belt in North Sichuan Guzhong Depression (Fig. 1). The surface topography is mainly low mountain hills with Lower Cretaceous or Upper Jurassic formations outcrops. Strata of Da'anzhai member, which located in Upper Ziliujing Formation of Lower Jurassic, are mainly dark gray, black shale with shell limestone and argillaceous shell limestone interbeds. The thickness is $60-120 \mathrm{~m}$. According to lithologic character, electric nature and sedimentation cycle, Da' anzhai member can be divided into $D_{3}, D_{1}{ }^{3}$ and $D_{1}$ segments, and reservoirs are widely distributed in all three (Fig. 2).

During Da'anzhai sedimentation, Sichuan Basin had experienced the biggest lake invasion within early Jurassic, which formed an inland lake sedimentary system surrounded by Longmen Mountain ancient land, Dabashan Mountain ancient land and Kangqian ancient land [7-9]. Consistent with the regional sedimentary evolution, north central Sichuan Basin had experienced 3 sedimentary stages: early lacustrine transgression stage, mid-term largest transgression stage and late lacustrine reliction stage. The lacustrine basin 


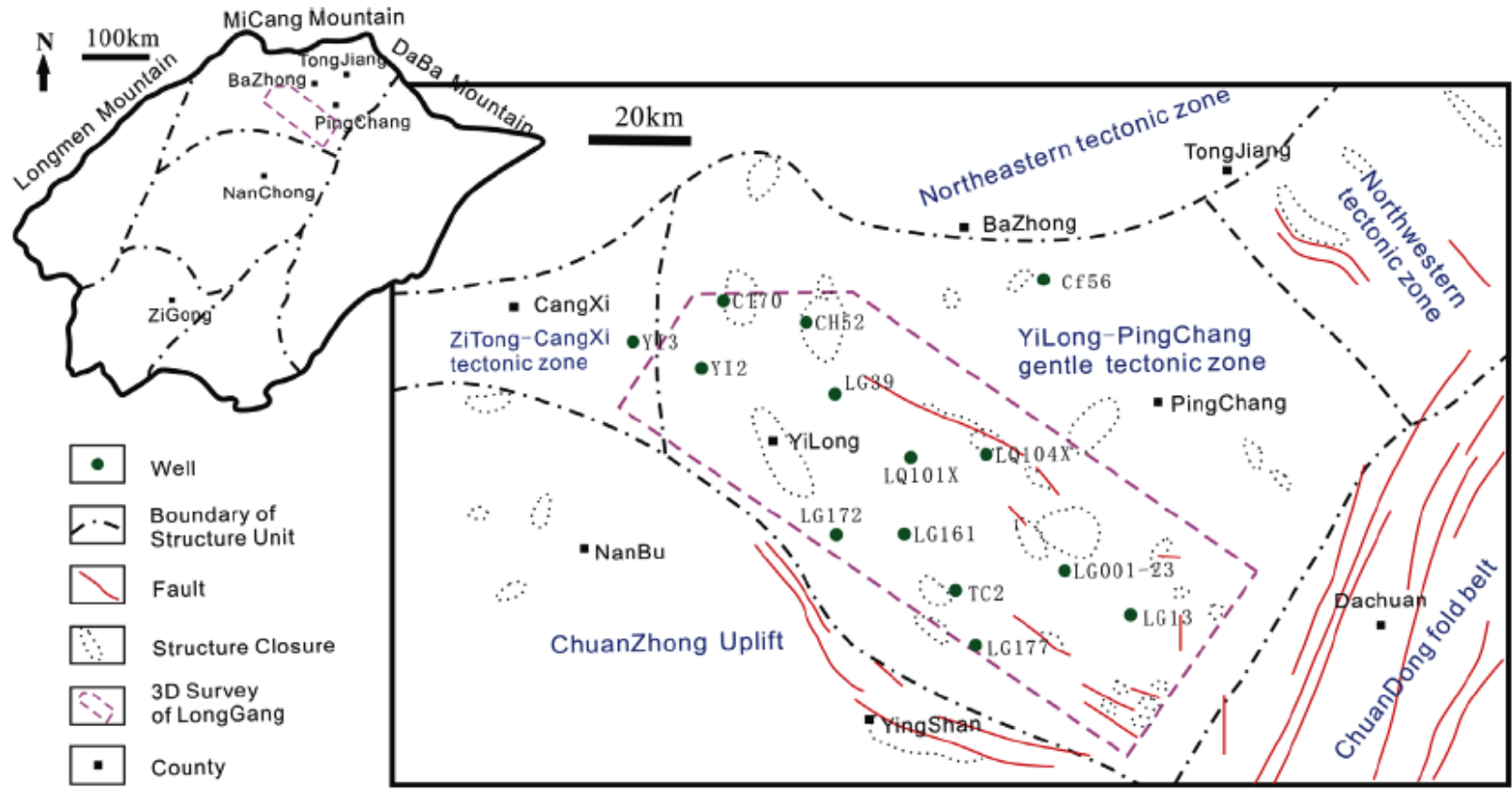

Fig. (1). Location map shows the structural location of study area in Central Sichuan Basin.

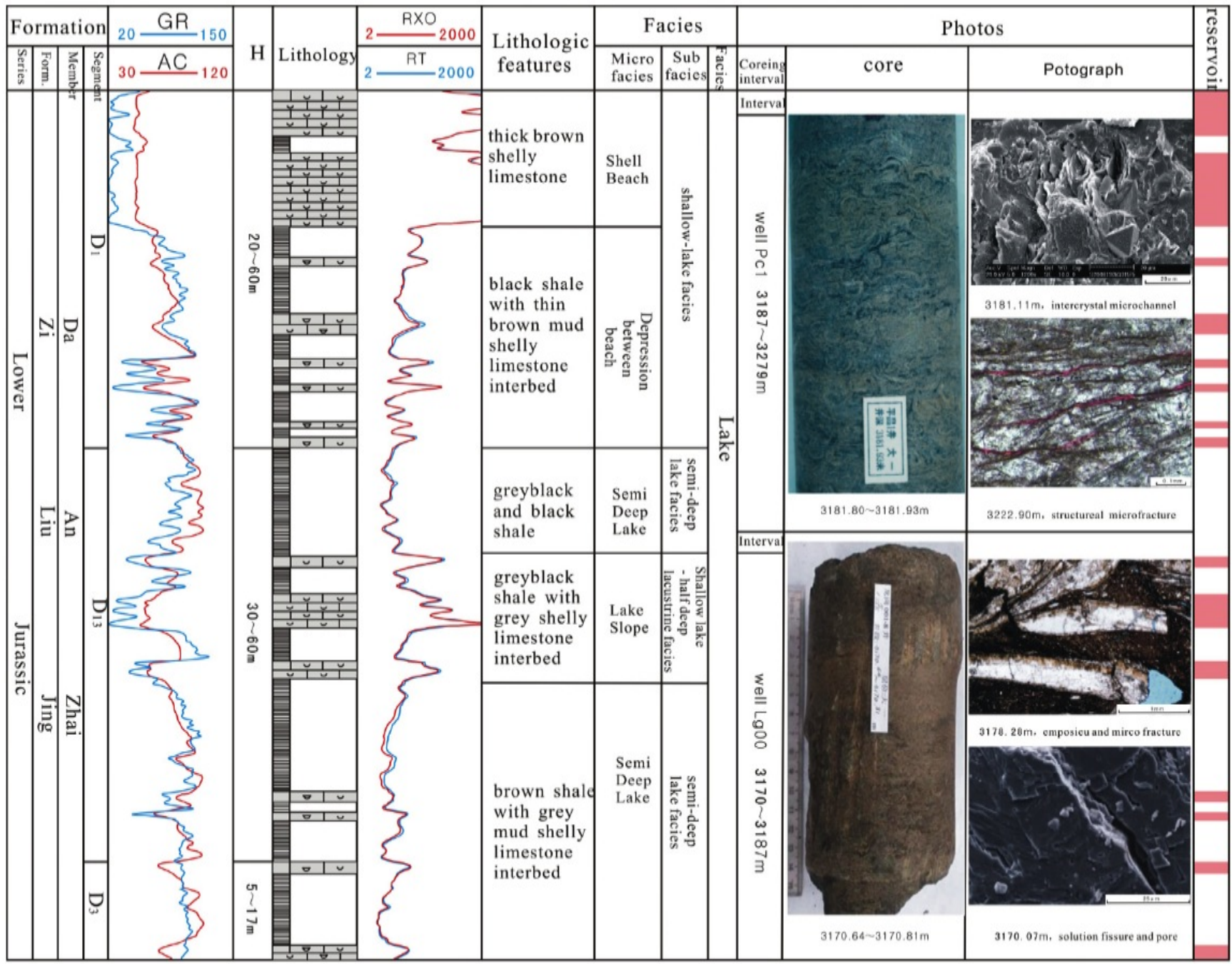

Fig. (2). Comprehensive stratigraphic column of Da'anzhai Member in study area. 

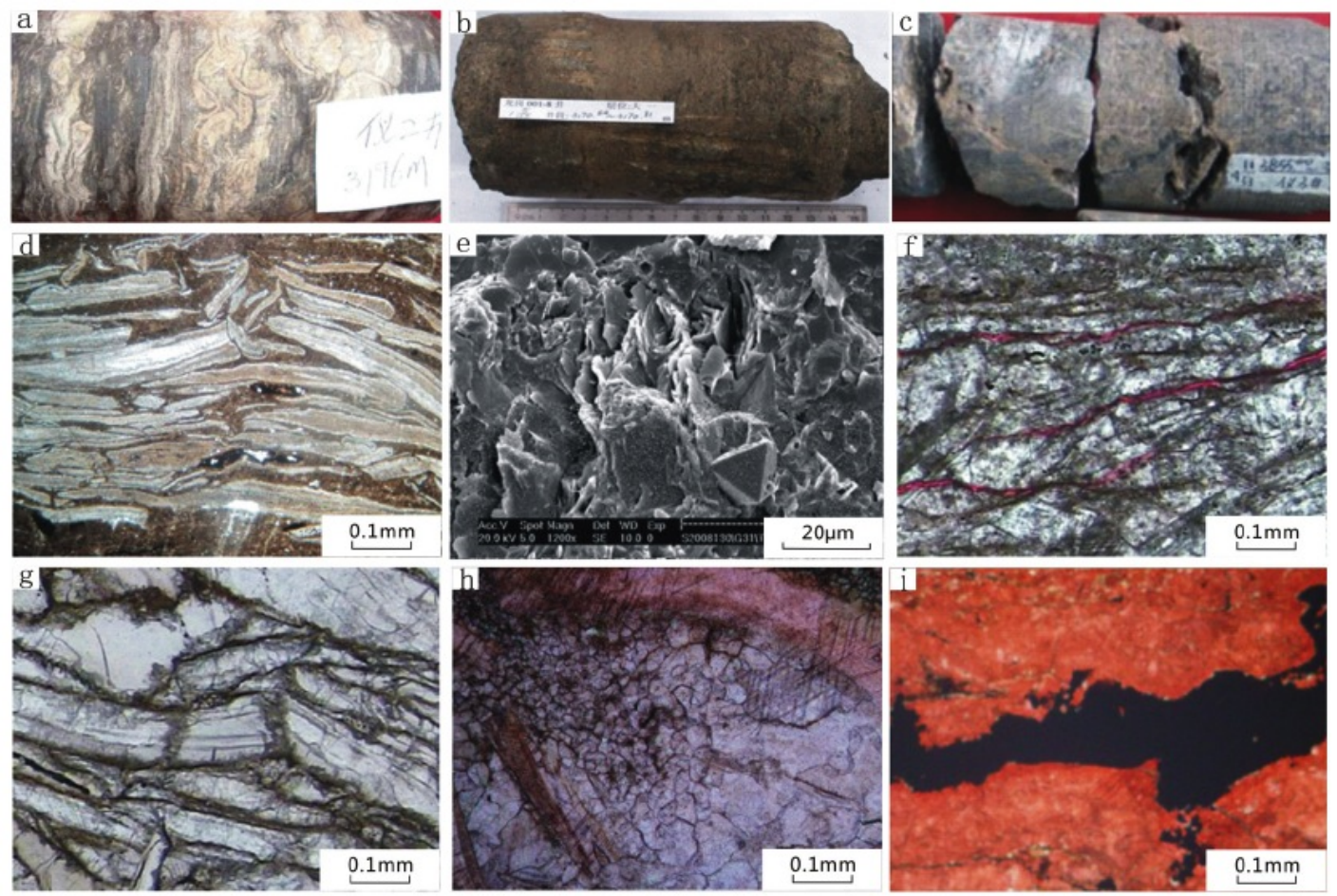

Fig. (3). The typical characteristic of reservoir and reservoir spaces in Da'anzhai Member.

Table 1. Reservoir porosity and permeability in Da'anzhai member in study area.

\begin{tabular}{|c|c|c|c|c|c|}
\hline \multirow{2}{*}{ Well } & \multirow{2}{*}{ Sample Number } & \multicolumn{2}{|c|}{ Porosity/\% } & \multicolumn{2}{c|}{ Permeability/10 $^{-3} \boldsymbol{\mu} \mathbf{m}^{2}$} \\
\cline { 2 - 6 } & & Range & Average & Range & 0.0568 \\
\hline \hline LG001-8 & 26 & $0.61 \sim 4.17$ & 1.26 & $0.0025 \sim 0.967$ & 0.0591 \\
\hline PC1 & 86 & $0.18 \sim 3.22$ & 0.63 & $0.0026 \sim 1.46$ & 0.0133 \\
\hline LQ104X & 44 & $0.43 \sim 0.64$ & 1.00 & $0.0000538 \sim 0.326$ & $0.0000538 \sim 1.46$ \\
\hline Total & 156 & $0.18 \sim 4.17$ & 0.84 & 0.0458 \\
\hline
\end{tabular}

Table 2. Comparison of physical property between samples with and without fractures in Da'anzhai member in study area.

\begin{tabular}{|c|c|c|c|c|c|c|}
\hline Well & \multicolumn{3}{|c|}{ Samples without Fractures } & \multicolumn{3}{|c|}{ Samples with Fractures } \\
\hline G2 & 19 & 0.83 & 0.0336 & 3 & 1.2 & 0.19 \\
\hline G3 & 33 & 0.84 & 0.0834 & 6 & 1.06 & 14.7 \\
\hline G6 & 19 & 0.87 & 0.05 & 4 & 1.13 & 35.5 \\
\hline Total & 106 & 0.85 & 0.0562 & 16 & 1.08 & 18.8 \\
\hline
\end{tabular}

center and depocenter were both in Yilong and Yingshan areas, where deep to semi-deep lacustrine black shale deposited. From the center to margin, sedimentary facies pass from deep water facies to shallow lake and lacustrine shore facies, distributed in ring shape from plane view.

\section{RESERVOIR CHARACTERISTICS}

\subsection{Reservoir Rock Types}

Predecessors have made a number of basic researches on Da'anzhai reservoirs [10-12]. Based on slice analysis and 
SEM results, rock types of Da'anzhai reservoirs can be simply divided into crystalline shell limestone and argillaceous shell limestone.

(1) Crystalline shell limestone: Main lithology is graybrownish gray, medium thick -thick, fine- very fine crystalline shell limestone (Fig. 3a, 3d); which is dense and characterized by strong recrystallization [13]. Shell content is generally greater than $90 \%$. Cement between shell grains is usually mud microcrystalline calcite or calcsparite. Mineral component is mainly micritic calcite, also containing a small amount of clay, siliceous mineral, terrigenous clastic, organic matter and pyrite. Texture component consists of grained clasts and interstitial material. The total content of grained clasts is approximately $56 \%$, including $92 \%$ of lamellibranch as prime component, and ostracods and gastropods as secondary. While the interstitial material is mainly microcrystalline, with total content of $41 \%$. This kind of reservoir is often developed at shell beach in shallow lake with strong hydrodynamic energy, most of which was distributed in midupper D1 and D3 in study area.

(2) Argillaceous shell limestone: The color is gray, grayish yellow (Fig. 3b). Composition is mainly carbonate with content greater than $50 \%$, clay with content less than $25 \%$; and a small amount of terrigenous clastics. Bioclastics are lamellibranch, gastropods and ostracods. Shell grains are directionally arranged, and part of which are in undercompacted ridge-shaped texture. Diagenesis is weak. As a result, primary composition and texture of shell grain is well protected. Under the orthogonal light, the original flake and fibril-like textures of shell can be seen, as well as wavy extinction [14]. As the main cement is clay, there is barely no calcite between shell grains. This kind of reservoirs is often developed in shallow to semi-deep lacustrine slope and semi-deep lacustrine facies with lower hydraulic energy, most of which was distributed in lower D1 and D13 in the study area.

\subsection{Reservoir Property}

According to analysis of cores from Da'anzhai member in the study area (Table 1), the reservoirs are dense and of bad physical property. As porosity range is $0.18 \% \sim 4.17 \%$ with average of $0.84 \%$ and permeability range is $5.38 \times 10^{-}$ ${ }^{8} \mu \mathrm{m}^{2} \sim 1.43 \times 10^{-3} \mu \mathrm{m}^{2}$ with average of $0.0458 \times 10^{-3} \mu \mathrm{m}^{2}$, the reservoirs are classified as ultra-low porosity and low permeability type. However, the development of fractures can significantly increase the porosity and permeability, and therefore make a contribution to reservoir property improvement (Table 2). Based on analysis of mercury penetration data, shell limestone reservoirs of Da'anzhai are characterized by high displacement pressure (31.6 MPa) and median capillary pressure $(146.2 \mathrm{MPa})$, high mercury unsaturation $(64.5 \%)$, extra small maximum connected pore throat radius $(0.0357 \mu \mathrm{m})$ and median pore throat $\operatorname{radius}(<0.1 \mu \mathrm{m})$, and ultra-low ejection efficiency $(9.44 \%)$. This indicates undevelopment of reservoir pores and bad pore configuration.

\subsection{Reservoir Space Type}

According to pore size and genesis, and combining with core slice and casing slice data, scan electron microscope results and core observation, the reservoir space can be divided into 2 types: macro pores and fractures and micro pores and fractures (Table $\mathbf{3}$ ).

1. Macro pores and fractures: The structural fractures and dissolved pores are generally with low filling degree and often semi-filled with clay or secondary mineral such as calcite, quartz and so on. Hydrocarbon shows like oil stain and oil spot can be seen in these reservoir spaces (Fig. 3c). 95\% of macro fractures are horizontal and low angle structural fractures. Development degree of macro pores and fractures is relatively low, but their contributions to reservoir effectiveness improvement are significant.

2. Micro pores and fractures: Micro pores are generally characterized by small pore radius and bad connectivity (Fig. 3e). Among these micro pores, there are barely no primary pores left. The only remaining are matrix intergranular pore and residual pores formed by support and shelter of shell grains. Secondary pores are basically isolate intergranular and intragranular micro dissolved pores in relatively large quantities. Micro fractures are usually composed by structural movement (Fig. 3f) with wide distribution and good connectivity.

Overall, reservoir space of Da'anzhai is mainly contributed by dissolved pores and micro fractures, followed by macroscopic structural fractures and secondary pores, hardly no primary pores. And permeation paths are fractures. The porous and permeable reservoirs are intensively developed in the upper section of Da'anzhai.

a- Core photograph, grayish brown shell limestone from Y2 well in D1 segment at 3196m, shell fragments, wellsorted; b- Core photograph, grayish brown shell limestone from LG001-8 well in D1 segment at 3170.64-3170.8m; cCore photograph, dark brownish grey shell limestone from Y2 well in D1 segment at 3194.65-3194.95m, structural fractures semi-filled with calcite, beadlike dissolved pores along fractures filled with oil stain; d- Slice under plane-polarized light $\times 25$, powder crystalline shell limestone from LQ104X well in D1 segment at $3499.45 \mathrm{~m}$; e- SEM photograph, clay mineral intergranular pores, PC1 well, $3181.11 \mathrm{~m}$; f- Casing slice under plane-polarized light $\times 25$, fine powder crystalline shell limestone from PC1 well at $3222.9 \mathrm{~m}$, bifurcate micro fractures; g- Slice under plane-polarized light $\times 25$, argillaceous fine powder crystalline shell limestone from LG001-8 well at $3170.14 \mathrm{~m}$, shell fragments aligned in direction; hShell limestone from PC1 well at $3223.9 \mathrm{~m}$, with ankerite cementation; i- Intergranular dissolved pore of shell limestone, filled with asphalt, LG2 well, $3200 \mathrm{~m}$.

\subsection{Reservoir Type}

The reservoirs of Da'anzhai in the study area are dense and of bad properties with ultra-low porosity, low permeability and poor pore throat configuration. Although matrix pores could make a certain contribution to production, without development of fractures, it's very hard to obtain commercial oil and gas flow.

The former exploration and development proved that high capacity wells from Da'anzhai member have provided evidences of good hydrocarbon shows such as blowout, well 
Table 3. The classification of reservoir space in Da'anzhai Member in study area.

\begin{tabular}{|l|l|l|l|l|}
\hline \multicolumn{1}{|c|}{ Type } & \multicolumn{2}{|c|}{ Category } & \multicolumn{1}{c|}{$\begin{array}{c}\text { Genetic Features } \\
\text { Occurrence }\end{array}$} \\
\hline \hline $\begin{array}{l}\text { Macro pores \& } \\
\text { fractures }\end{array}$ & Dissolved pores & $\begin{array}{l}\text { Formed by dissolution during diagenesis; often distribute along structure fractures; pore } \\
\text { sizes vary greatly. }\end{array}$ & High \\
\cline { 2 - 5 } & Structural fractures & Formed by structural movement; mainly are small with low angle. & Medium \\
\hline $\begin{array}{l}\text { Micro pores \& } \\
\text { fractures }\end{array}$ & $\begin{array}{l}\text { Micro } \\
\text { pores }\end{array}$ & Primary pores & $\begin{array}{l}\text { Indicate the remaining micro pores due to grain support between shell grain and matrix } \\
\text { materials. }\end{array}$ & Low \\
\cline { 2 - 5 } & Secondary pores & Mainly indicate intergranular and intragranular micro dissolved pores. & Medium \\
\cline { 2 - 5 } & Micro fractures & $\begin{array}{l}\text { Mainly composed by micro fractures formed by structural movement; also including a } \\
\text { few fractures formed by diagenetic contraction and differential compaction. }\end{array}$ & High \\
\hline
\end{tabular}

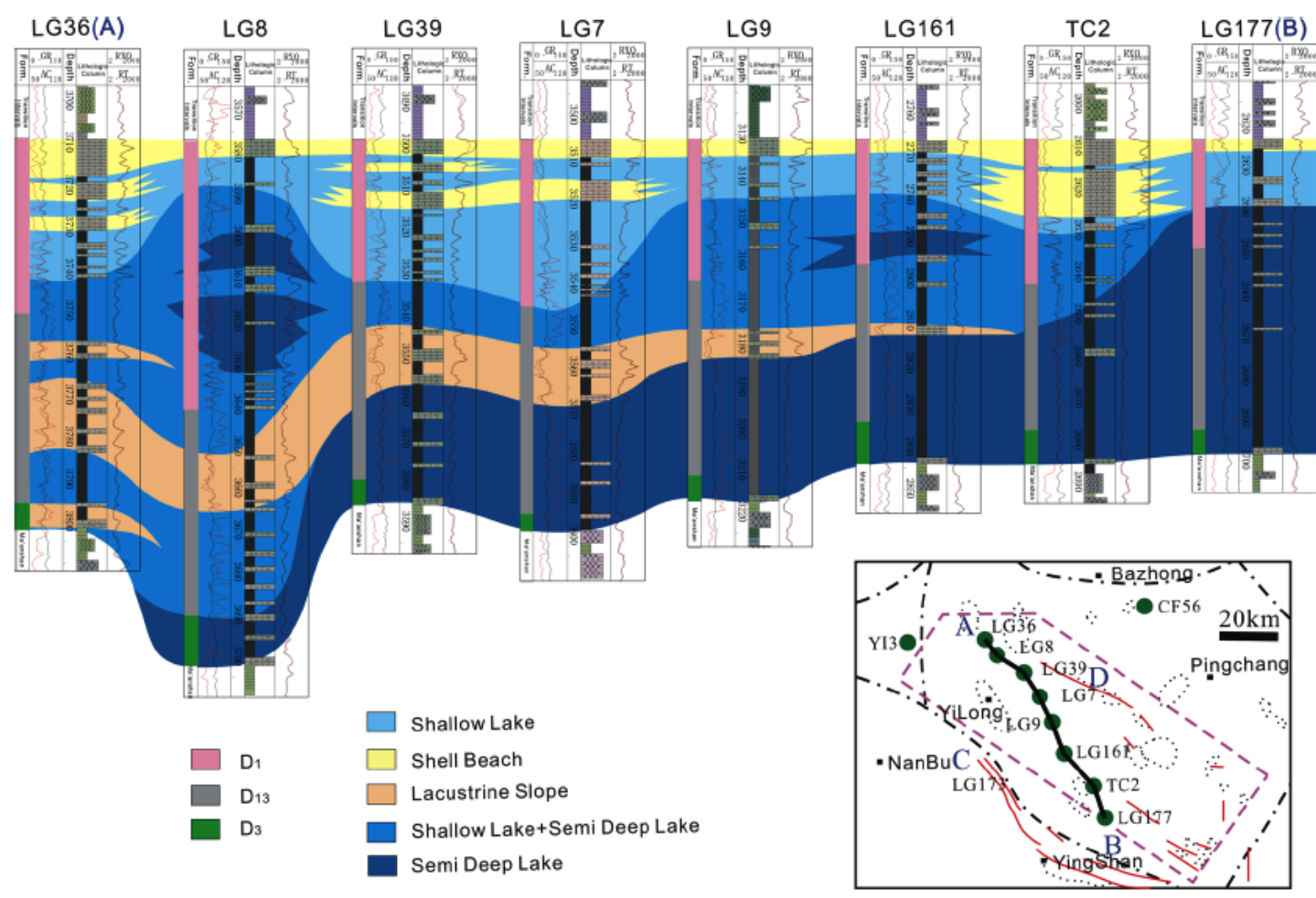

Fig. (4). Comparison diagram of sedimentary facies from Well LG36 to Well LG177 in Da'anzhai member.

kick, oil cut, etc., which indicate that fractures have played a significant role. Almost all wells with high testing production show responses of fractures; in contrast, hardly any wells with no fracture responses obtained commercial production. Production curves can be divided into two stages. At first, the initial production and pressure are high but with rapid decline, which suggests a fracture-dominated production feature. Later, the production is low with a slow decline of pressure, which means pores make more contributions to the production. Therefore it can be concluded that reservoir type of Da'anzhai is pore - fracture type.

\section{CONTROL FACTORS OF RESERVOIR DEVEL- OPMENT}

The reservoir development is controlled by sedimentation, diagenesis and tectogenesis together. Sedimentation is the foundation, which not only determines the reservoir distribution, but also influences the type and intensity of later diagenesis. Diagenesis and tectogenesis are the key factors, which determine the reservoir quality and property.

\subsection{Sedimentation}

Sedimentation provides the foundation of reservoir development and controls the distribution and characteristics of biolithite reservoirs. Shallow lacustrine shell beach facies developed in a relatively high position with strong hydrodynamic energy. Shells can be sorted well with less clay. Middle-thick crystalline shell limestone was developed. Although strong compaction had destroyed the primary pores, fragileness of shell was beneficial to the formations of dissolved pores and structural fractures forming by later dissolution and tectogenesis. Numbers of drilling result suggest, 
crystalline shell limestone in high energy shell beach is not only of thick layer but also pure and brittle, and development of structural fractures and dissolved pores provides effective reservoir space.

There was plenty of argillaceous shell limestone developed at shallow to semi-deep lacustrine slope. Due to the existence of argillaceous components, the shell limestone was less influenced by diagenesis and of lower degree of cementation and replacement. As a result, the primary pores were preserved, which provided the foundation for high quality reservoirs of Da'anzhai member. In conclusion, shallow lacustrine shell beach and shallow to semi-deep lacustrine slope are the favorable reservoir facies of $\mathrm{Da}$ 'anzhai in the study area as shown in Fig. (4).

\subsection{Diagenesis}

For carbonate reservoir, diagenesis is complicated, and can be divided into destructive diagenesis and constructive diagenesis. Compaction, pressolution and cementation are primary destructive diagenesis, which reduce the reservoir porosity and permeability; in contrast, dissolution is the constructive diagenesis which can improve reservoir properties.

Destructive diagenesis: including compaction, pressolution and cementation. The evidences of strong compaction and pressolution are: 1) crushed shell fragments aligned in closely parallel direction (Fig. 3g); 2) shell grains contraction in linear shape or concave-convex mosaic shape; and 3) stylolite. Compaction reduced primary porosity, forced the plastic minerals to align directionally and limited reservoir connectivity as shown in Fig. (3h). Cementation is to cement grains and other components together into solid rocks, which also reduce storage spaces of reservoirs [15]. Cements include clay, adelforsit, quartz, calcite, and ankerite. Core slices observation suggests part of the reservoirs experienced multi-stage cementations.

Constructive diagenesis: mainly the dissolution. Dissolution in the study area is divided into diagenetic dissolution and tectonic dissolution. The former made contributions to intergranular dissolved pores and moldic pores (Fig. 3i), while the latter was to re-dissolve the early filled dissolved pores and enlarge the fractures. Dissolved pores formed by dissolution constitute the main storage spaces of shell limestone reservoirs in Da'anzhai.

\subsection{Tectogenesis}

As the reservoir properties are ultra-low porosity and low permeability in the study area, fractures play an important role in reservoir formation and hydrocarbon production. During Yanshan and Himalayan movements, the study area has experienced frequent and strong tectogenesis. Accompanied by regional structural fractures and local structural closures, a great number of structural fractures have been developed at anticline wings and active fault walls, which proved good conditions for dissolution. Fractures and micro fractures can often be seen in both slices and cores observations (Fig. 3c, 3f). And different levels of fracture response can be detected from geo logging or mud logging. Structural fractures not only can significantly improve the permeability of reservoirs, and also are the essential conditions of high production.

\section{CONCLUSION}

1. The reservoir types of Da'anzhai in the study area are crystalline shell limestone and argillaceous shell limestone. The reservoirs properties are ultra-low porosity and low permeability, which can be significantly improved by fractures.

2. Dominant reservoir space of Da'anzhai in the study area is of pore-fracture type, constitutive of micro fractures accompanied by dissolved pores. The pore throat configuration is not good.

3. The reservoir development is controlled by sedimentation, diagenesis and tectogenesis together. Favorable micro facies for reservoir development are shallow lacustrine shell beach and shallow-semi deep lacustrine slop. Dissolution is the main constructive diagenesis to improve reservoir porosity and permeability. Structural fractures are necessary for reservoir effectiveness and high production.

\section{CONFLICT OF INTEREST}

The authors confirm that this article content has no conflict of interest.

\section{ACKNOWLEDGEMENTS}

This work was financially supported by the National Natural Science Foundation of China (41302076), the Youth Science Foundation of Hebei Education Department $(\mathrm{QN2} 2015255)$ and the Youth Science Foundation of Shijiazhuang University of Economics(QN201503).

\section{REFERENCES}

[1] Z. Shuxin, "The implications of petroleum geology of lacustrine carbonate rocks," Experimental Petroleum Geology, vol. 15, pp. 261-369, Dec. 1993

[2] Z. Rongcai, "High-Resolution sequence stratigraphy of Daanzhai formation, lower Jurassic in Sichuan Basin", Acta Sedimentologica Sinica, vol. 16, pp. 42-49, Jun. 1998

[3] L. Jun, and W. Shiqian, "The main factors controlling hydrocarbon accumulation in the Jurassic of Pingchang-Langzhongarea in the Sichuan Basin and its exploration strategies", Natural Gas Industry, vol. 30 , pp. 16-21, Mar. 2010

[4] Q. Ling, "Evaluation of oil and gas exploration favorable block in the Jurassic of the Jurassic system in Sichuan Basin", M.S. thesis, Southwest Petroleum University, Chengdu, ON, China, 2013

[5] L. Digang, R. Longhui, D. Tanshen, H. Zixin, O. Jian, L. Qunshan, and $\mathrm{H}$. Wenyuan, "A re-recognition of the prospecting potential of Jurassic large-area and non-conventional oils in the central northern Sichuan Basin", Acta Petrolei Sinica, vol. 132, pp. 8-17, Jan. 2011

[6] S. Wei, L. Zhiwu, Zhangwei, F. Feng, Z. Meng, and W. Wenhui, "Petroleum exploration prospect of Lower Jurassic Da anzhai Member, north-centre of Sichuan Basin, China", Journal of Chengdu University of Technology, vol. 41, pp. 1-7, Jan. 2014

[7] G. Zhengwu, D. Kangling, and H. Yonghui, "The formation and Evolution of the Sichuan Basin, Beijing", pp. 1-200, 1996.

[8] T. Chongguang, "The evolution of tectonic and the accumulation of oil-gas in the Sichuan Basin, Beijing”, pp. 1-128, 1992.

[9] E. Liu, Sichuan expected oil geology of editorial committee, Sichuan Oil Province, China petroleum geology, vol. 10, Beijing, pp. $1-516,1989$.

[10] X. Lin, W. Xingzhi, Z. Fan, L. Yonghong, Q. Wenbin, and Z. Wei, "A study of the reservoir of Da'anzhai member in WenjingMingyue area of Sichuan Basin", Geology in China, vol. 30, pp. 1393-1398, Oct. 2010

[11] X. Shuanghui, C. Hongde, L. Liangbiao, Q. Lijun, Z. Junshou, C. Anqing and X. Shenglin, "Reservoir characteristics of Da'anzhai 
segment of Quxian area in northeast of Sichuan, China," Journal of Chengdu University of Technology, vol. 40, pp. 200-208 Mar. 2013.

[12] C. Wei, H. Yi, N. Chao, Z. Yin and H. Gangfu, "Reservoir characteristics and controlling factors of Da'anzhai member in lower Jurassic, Central Sichuan," Journal of Southwest Petroleum University, vol. 35, pp. 7-14, Sep. 2013

[13] N. Chao, H. Yi, H. Gangfu, G. Mingfeng and Z. Litao, "Cognition and significance of lower jurassic Da'anzhai organic muddy shell limestone reservoir in central Sichuan Basin", Marine Origin Petroleum Geology, vol. 17, pp. 45-46, Apr. 2012.

[14] Z. Heqing, "Skeletal aragonite preserved in Da'anzhai Limestone of Jurassic Sichuan," Natural Gas Industry, vol. 4, pp. 22-26, Mar 1984

[15] H. Hengshuan, "The performance relationship of diagenesis and reservoir in Da anzhai member in Sichuan North," Petroleum Geology \& Experiment, vol. 11, pp. 62-75, Apr. 1989.

Received: May 26, 2015

(C) Jiangmin et al.; Licensee Bentham Open.

This is an open access article licensed under the terms of the (https://creativecommons.org/licenses/by/4.0/legalcode), which permits unrestricted, noncommercial use, distribution and reproduction in any medium, provided the work is properly cited. 